\title{
The Prevalence of Academic Dishonesty and Perceptions of Students towards its Practical Habits: Implication for Quality of Education
}

\author{
Feyisa Mulisa*
}

\author{
Department of Psychology, Bahir Dar University, Bahir Dar, Ethiopia
}

\begin{tabular}{|c|c|}
\hline Abstract & Article Info \\
\hline \multirow{3}{*}{$\begin{array}{l}\text { The issue of quality education is the today's concern of all educational stakeholders. One } \\
\text { means of realizing this quality in higher education institutions is to alleviate academic dishonest } \\
\text { behaviors that hamper the creativity and analytical skills of students. This study examines the } \\
\text { prevalence of academic dishonesty behaviors, perceptions of students regarding academic } \\
\text { dishonesty behaviors, and to tests whether there is gender difference in exam related and } \\
\text { assignment related academic dishonesty behaviors as obtained from the self report of } 352 \\
\text { Bahir Dar University (BDU) undergraduate students. The findings showed that academic } \\
\text { dishonesty was prevalent among the students and majority of the students committed academic } \\
\text { dishonesty at least once. The practices of dishonesty behaviors were more prevalent in } \\
\text { assignment related works than in exam related works. In some aspects of academic dishonesty } \\
\text { behaviors, there was significant gender difference both in prevalence of academic dishonesty } \\
\text { behaviors and how the students perceive behaviors related to academic dishonesty. }\end{array}$} & $\begin{array}{l}15 \\
015 \\
015 \\
\end{array}$ \\
\hline & \\
\hline & \\
\hline
\end{tabular}

\section{INTRODUCTION}

Academic dishonesty is one of the oldest challenges in instructional setting (Spaulding, 2009) however it remains one of the most challenging issues with the advancement of technology today (Mebratu, 2014; Koss, 2011; Brimble and Stevenson-Clarke, 2006). It can be defined as tampering with, altering, circumventing, or destroying any educational material or resources in a manner which deprives any students' fair access to resource (Lucas and Bernstein, 2005). It is also explained in form of fabricating false ideas that wasn't claimed by the teacher and hiding real information from others (Fawkner and Keremidchieva 2004). In academic contexts, dishonesty is more than cheating at exam, assignments and papers. It includes cheating, fraud and plagiarism, the theft of ideas and other forms of intellectual properties whether they are published or not (Jones, 2011). These dishonesty behaviors can be committed either knowingly or unknowingly by the students to earn better academic credits (Ibid). It is believed that the quality of education cannot be ensured if academic dishonesty is being committed in school setting.

Academic dishonesty is a problem that starts in primary schools and goes on through colleges and universities (Mebratu, 2014; Koss, 2011). For the purpose of this study, the researcher concentrates on academic dishonesty that is occurring in the higher institutions. Higher institutions are the places where citizens are prepared for advanced future careers and responsibilities. They prepare their candidates to enter professional careers by identifying the demands of the current community with the goals of developing the candidates' creativity, insight, and analytical skills (Lupton, et al. 2000). More significantly, higher institutions yield the educators of tomorrow who are morally responsible to increase the awareness, knowledge, skills, and values needed to create a just and sustain a future (Cortese, 2003). These institutions achieve their goals when they acquaint their students with these complex intellectual skills, problem solving abilities and harmonized personality. Hence, any form of academic dishonesty behavior impedes the achievement of these missions virtually. In higher education there are five fundamental values of academic integrity: honesty, trust, fairness, respect, and responsibility (CFAl, 1999). Further Brimble and Stevenson-Clarke (2006) stated that the role of higher education is much greater than preparing students for jobs as contributing to the fulfillment of human and societal potential, the advancement of knowledge and social and economic progress. In general, academic dishonesty deters the achievement of these fundamental values of education and diminishes the progress of creativity.

Particular, a rampant form of academic dishonesty disables the goals of higher education institutions by creating corrupted and unethical citizens. According to Tefera and Kinde (2010), the effect of academic dishonesty is long-lasting and catastrophic in many instances. The inferences of academic dishonesty on a quality of education could be considered from three major perspectives according to Brimble and Stevenson-Clarke (2005). First, those students who committed dishonesty unfairly benefited from higher grades so that the equity 
Feyisa Mulisa

and efficiency of the instructional measurement might be jeopardized and measuring students' relative ability is not possible. Second, it reduces the students' effort to achieve the goals of instruction both in the advanced study and the application of instructional objectives. The third is related to the ethical values of dishonest behaviors. The authors claimed that those students who are ethically corrupted and do not respect academic integrity at higher institutions might not respect the integrity of their future professionals and careers. In higher education maintaining academic integrity is not a luxury but essential for survival in the global knowledge, skills and discoveries (Teshome, 2004).

The behaviors of academic dishonesty either directly or indirectly affect the quality of education as students seek mere credential by committing dishonesty behaviors which in turn intimidates the value of education and kills the progress of scientific cultures (Brimble and Stevenson-Clarke, 2006). When the students commit academic dishonesty, they are lying themselves and the academic institution for merely gaining academic credit without hardworking. They are lying themselves as their CGPA reflects not their own true work and witnessed one's right meritness. On the other hand, academic integrity helps the students to grow professionally and to become creative which dishonesty students would be deprived of. They are also lying their academic institution as accredited without performing their duties and responsibilities and violating against the regulations of the institution.

Academic misconduct can be committed in many forms. According to Lucas and Bernstein, these misconducts can be seen in terms of cheating, fabrications, facilitating infractions of academic integrity, bribes, favors and threats. Another form of academic dishonesty is plagiarism. Plagiarism is representing the words or ideas of another as one's own in any academic endeavor (Lucas and Bernstein 2005). According to the writers, plagiarism includes copying another's work or working with another person when both submit similar papers without authorization. The same authors finalize the types of academic dishonesty by including bribes, favors and threats. Further, there are forms of infractions that attempt to bribe, promising favors to or making threats against any person with the intention of affecting his/her grade or evaluation of academic performance (lbid).

Basically, academic dishonesty occurs as students' concern become to earn better grades and accreditations than to grow professionally (Bushweller, 1999). There are some research evidences that show why students commit academic dishonesty (Meizlish, 2005; Koss, 2011; Mebratu, 2014). However these grounds can be classified under developmental or situational factors (Roberts and Haijew, 2009). According the authors, values may be socially created between people and embedded in a culture. Some of these values are situational and related to external contexts whereas others' values are developmental and related to internal development. Situational factors are those related to competition and might affect the students' academic credit. These variables include a concern to achieve good grades, test anxiety, the classroom environment and relative risk of detection, institutional policies on academic honesty, and performance and achievement issues (Higbee
Sci. Technol. Arts Res. J., April-June 2015, 4(2): 309-315

and Thomas, 2002). Developmental factors that cause academic dishonesty involve poor study skills, poor time management, lack of preparation, lack of skills to find resources, unwillingness to follow recommended good practice, inability to seek appropriate help, and low intrinsic interest in a given subject (Sheard, Carbone, and Dick, 2002) as cited in (Roberts and Haijew, 2009). There are further research evidences that show academic dishonest behavior be related to family expectation, peer pressure and teachers commitment (Koss, 2011; Mebratu, 2014).

Further the rate of dishonesty behaviors can be affected by students' demographical factors such as age, gender, scholastic ability, family status, financial stress, attitudes toward cheating behavior and the feelings of alienation (Meizlish, 2005). Meizlish further stated that classroom context variables such as perceived work load, competitiveness, class size, testing environment and the institutional factors such as honor codes, explicitness of academic integrity policies, clarity of sanctions can be considered as the reasons of academic dishonesty. In addition to demographic and attitudinal variables, genders have also hypothesized to be related to academic dishonesty (Lupton et al., 2000) however there are mixed findings regarding gender difference on academic dishonesty. There is a research finding that suggested men commit academic dishonesty more often than women (Calabrese and Cochran, 1990) where as there is also a research evidence that found out female college students commit academic dishonesty more often than their male students counterpart do (Leming, 1980).

Building the culture of honesty and academic integrity in higher education institutions is beyond the mere seek for the quality of education and promote the fundamental values of integrity. It cultivates people with strong selfreliant emotions and creative skills. But with the advancement of modern information technologies, there is a shift on how academic dishonesty is being committed among the students. There is evidence that shows both the exploitation of technology and traditional means of cheating occur when the students believe that committing academic dishonesty is not a serious behavior (Etter et al. 2006). Academic misconduct behaviors can be committed for different reasons. The first is the situational and contextual factors that force students to commit the dishonesty (Roberts and Haijew, 2009) where the second is internal attitude and perception of students towards the academic dishonest behaviors (Meizlish, 2005). Chiesl (2009) further extends that perceptions like little chance of being caught, no punishment if get caught and everyone else is doing it are among common reasons of academic dishonesty. Academic dishonesty can be committed by best students as their concern become to get the top of the classes, by middle students to remain competent and by low achiever students to earn better grades (Fawkner and Keremidchieva, 2004).

Though many studies have been conducted on the issue addressing academic dishonesty, the only common share of these findings is the trend that a number of students participate in academic dishonesty behaviors. There are huge gaps in the literature on figuring out why students choose to commit academic dishonesty and the trends of its prevalence. Particularly, the figures that show the degree of academic dishonesty are recurrently inconsistent with each other overtime and across cultures. 
According to Bowers (1964), $75 \%$ college students admitted cheating in their courses at least once, in other study between $70 \%$ and $82 \%$ of U.S. college undergraduate students engaged in some form of cheating during their college careers (Sterm and Havlicek, 1986) whereas Maramark and Maline (1993) claimed 95\% of college students have been dishonest at least once in their academic careers. Fawkner and Keremidchieva (2004) stated that $80 \%$ of college students committed academic dishonesty at least once where as Tefere and Kinde (2010) stated that $96.4 \%$ of college students committed academic dishonesty related to exam at least once.

Based on these gaps and trends of academic dishonesty in the higher institutions, this research focused on the investigation the perception (what behaviors are or are not considered academic dishonesty and how they view dishonest behaviors) of Bahir Dar University students towards academic dishonesty, its degree of prevalence and to test whether there was gender difference in committing academic dishonesty. Despite the forms of academic dishonesty behaviors in higher institutions involve wide ranges behaviors like cheating on the exam, fabrication of data for papers and research projects, facilitating infractions and plagiarisms, this study limited its scope to the prevalence of academic dishonesty, how the students perceive the habits of academic dishonesty behaviors and to test whether there was significant gender difference in behaviors related to academic dishonesty among students of Bahir Dar University.

\section{MATERIALS AND METHODS \\ Design of the Study}

This study was aimed to investigate the students' perceptions about academic dishonesty behaviors and the degree of its prevalence as measured by a survey of students self report through close-ended and semi closeended questionnaires. Thus, this research employs quantitative approach to accomplish it objectives.

\section{Sample}

The target population of this research was Bahir Dar University regular undergraduate students of 2014/15 academic year. From the given population, 352 representatives were selected using multistage sampling from college of agriculture and environmental sciences, college of science and college of business and economics, and from faculty of education and behavioral science and faculty of humanity. First, the colleges and faculties were select using simple random sampling. Then, within a given colleges and faculties, the representative samples were selected using stratified random sampling to include students of different cohorts and both sexes. The gender structure of the representative samples were 208 male and 144 female undergraduate students.

\section{Instruments}

This study utilized quantitative research approaches. Hence, in order to gather data, the tool of the current research was questionnaire. The questionnaires were adopted from Michael Spaulding (2009) and organized in to two sections. The first section deals with the students self reported perception of the students about the behaviors of academic dishonesty. The second section investigates the prevalence of academic dishonesty. The questionnaires were pilot tested to validate its reliability before the administration. The split-half method was computed to test reliability. It was observed $\alpha=0.72$. The pilot test was mainly focused on the clarity and fitness of the questions for undergraduate students. A printed version of the questionnaire was administered to the participants in 2014/15 academic year in the face-to-face interactions.

\section{Analysis Techniques}

The collected data from participants through closeended questionnaire were analyzed quantitatively using statistical package (SPSS version 20). Based on the nature of data, percentages and chi-square tests were employed in the analysis of the organized data.

\section{RESULTS}

In this section the overview of students' responses that obtained from 352 participants were presented. The table 1 shows that $52.3 \%$ of the respondents reported they have had committed academic dishonesty at least once since they enrolled the university. Similarly $44.2 \%$ of the students accepted that they have had engaged in sending or sharing exam answer with other students during exam while 23.4 stated that they have received the answer from other students. In addition, $20.6 \%$ reported that they have copied from unauthorized piece of papers in the exam sessions. But as presented in the table- 1 , only $21.4 \%$ of the respondents reported they have had caught during committing academic dishonesty.

With respect to the gender difference, the finding of table-1 shows that there is significant gender difference in areas of sending or sharing one's answer with other students $\left(x^{2}=3.995, P<0.030\right)$, receiving answer from another student in exam session $\left(x^{2}=12.76, P<0.000\right)$, and being caught during committing the academic dishonesty. Finally, evidences show that there is statistically gender difference in the rate of caught during cheating on exam $\left(x^{2}=8.65, P<0.030\right)$. The figures show that female students largely involve in sending and receiving exam answer than males and more frequently caught by the instructors or/and invigilators than male students.

Table 1: Self reported prevalence of academic dishonesty among BDU undergraduate students

\begin{tabular}{lccccc}
\hline \multirow{2}{*}{\multicolumn{1}{c}{ Items }} & \multicolumn{4}{c}{ Responding “yes" (\%) and Chi square result } \\
\cline { 2 - 5 } & Male & Female & Total & $\boldsymbol{X}^{2}$ & $\mathbf{P}$ \\
\hline Committed academic dishonesty at least once & 48.5 & 58 & 52.3 & 2.94 & 0.086 \\
Sent or shared answer with other students during exam & 39.8 & 50.7 & 44.2 & 3.99 & 0.030 \\
Received answer from other students during exam & 16.7 & 33.3 & 23.4 & 12.76 & 0.000 \\
Copied from unauthorized piece of paper & 17.8 & 24.6 & 20.6 & 2.33 & 0.086 \\
Ever caught during committing cheating & 16 & 29.4 & 21.4 & 8.65 & 0.030 \\
\hline
\end{tabular}


Table 2: Frequency of exam-related academic dishonesty among those reported committed dishonesty

\begin{tabular}{|c|c|c|c|c|c|}
\hline Items & $\begin{array}{c}\% \text { of } \\
\text { Always }\end{array}$ & $\begin{array}{c}\% \text { of } \\
\text { Sometimes }\end{array}$ & $\begin{array}{c}\% \text { of } \\
\text { Occasionally }\end{array}$ & $\begin{array}{l}\% \text { of } \\
\text { Rarely }\end{array}$ & $\begin{array}{c}\% \\
\text { only once }\end{array}$ \\
\hline $\begin{array}{c}\text { Frequency of sent answer to other } \\
\text { students during exam }\end{array}$ & 16.4 & 47.8 & 10.4 & 11.9 & 13.4 \\
\hline $\begin{array}{l}\text { Frequency of received answer from } \\
\text { other students during exam }\end{array}$ & 16.7 & 36.1 & 11.1 & 27.8 & 8.3. \\
\hline $\begin{array}{l}\text { Frequencies of copied from } \\
\text { unauthorized piece of paper }\end{array}$ & 26.5 & 35.3 & 11.8 & 20.6 & 5.9 \\
\hline
\end{tabular}

The table 2 shows how much academic dishonesty was frequently occurring among those students that engaged in the dishonesty behaviors. As presented, $16.4 \%$ reported that they always commit dishonesty through sending answer to others or sharing answer with other students during exam whereas $47.8 \%$ reported that they committed sending answer to others or sharing answer with other students sometimes. But only $13.4 \%$ reported that they committed sending answer to others or sharing answer with other students only once. These results show that those students who were practicing sending their answer for another student or sharing their answer with other students, commit the misconduct more frequently with less academic faithfulness.
As presented in table 2,16.7\% students engaged the misconduct of receiving answer from other students always, $36.1 \%$ reported they engaged in the behavior sometimes and $8.3 \%$ reported they committed that behavior only once. The other form of dishonesty that presented in table 2 was the frequency of coping information from unauthorized piece of paper. The result shows that $26.5 \%$ of the respondents have always copied information from unauthorized piece of paper, $35.3 \%$ copied from unauthorized piece of paper sometimes and $20.6 \%$ copied from unauthorized piece of paper rarely during exam session.

Table 3: Exam related self reported students' perception towards academic dishonesty behaviors

\begin{tabular}{|c|c|c|c|c|c|}
\hline \multirow{2}{*}{ Items } & \multicolumn{5}{|c|}{$\begin{array}{l}\text { Responding "yes" (\%) and } \\
\text { Chi square result }\end{array}$} \\
\hline & Male & Female & Total & $x^{2}$ & $\mathbf{P}$ \\
\hline Cheating on exam is good for students if not caught & 26 & 30.6 & 27.8 & 0.894 & 0.205 \\
\hline $\begin{array}{l}\text { Giving exam or sharing answer with another student is a form of } \\
\text { helping the student }\end{array}$ & 10.6 & 27.8 & 17.6 & 17.35 & 0.000 \\
\hline Cheating is necessary part of learning processes & 15.4 & 19.4 & 17 & 0.992 & 0.197 \\
\hline Cheating facilitates the success in a given subject matter & 23.3 & 38.9 & 29.7 & 9.86 & 0.001 \\
\hline Success and accreditation is the only the target of learning & 45.6 & 59.2 & 51.1 & 6.15 & 0.099 \\
\hline Academic dishonesty disable one's professional development & 48.5 & 51.4 & 49.7 & 0.274 & 0.339 \\
\hline It is the responsibility of the instructor to prevent cheating & 51 & 52.8 & 51.7 & 0.112 & 0.410 \\
\hline If I would saw another student cheating I would report it to the instructor & 58.7 & 45.8 & 53.4 & 5.62 & 0.012 \\
\hline To avoid academic failure it is better to cheat for weak students & 26.2 & 34.7 & 29.7 & 2.84 & 0.056 \\
\hline Cheating is unfair in any form for all students & 68.3 & 77.8 & 72.2 & 3.83 & 0.032 \\
\hline
\end{tabular}

Table 3 presents the students' perception towards the academic dishonesty in the exam session. The result shows that $27.8 \%$ of the students perceive that cheating on exam is good for students if not caught. 17.6 of the students believe that giving exam and sharing answer with another student is a form of helping the student, $29.7 \%$ of the students perceive that cheating facilitate the success in a given subject matter and to avoid academic failure. Similarly nearly $50 \%$ of the students accept that academic cheating cant' affect one's professional development. The result further shows that $51.1 \%$ believe that success and accreditation is the only the target of learning whereas $29.7 \%$ of the students reported that to avoid academic failure it is better to cheat for weak students.

As shown in table 3, the result of the investigation $17 \%$ of the students that academic misconduct as necessary part of learning processes, whereas nearly $52 \%$ of the respondents reported that it is the responsibility of the instructor to prevent cheating. Only $53.4 \%$ of the students reported that they would report to their instructors and respective institutions if they saw another student is cheating and even $27.8 \%$ of the students believe that cheating is a fair activity.

With regard to gender differences, male and female students had significantly different self-reported academic dishonesty moral behaviors. Such behaviors were giving exam or sharing answer with another student is a form of helping the student $\left(x^{2}=17.35, P<0.000\right)$, cheating facilitates the success in a given subject matter $\left(x^{2}=9.86\right.$, $P<0.001$ ), the actions of reporting if others are practicing academic cheating $\left(x^{2}=5.62, P<0.012\right)$, and on the belief that cheating is unfair in any form for all students $\left(x^{2}=\right.$ $3.83, P<0.032)$. The finding of this research shows that female students were much less likely to feel that it was so bad to commit academic dishonesty on one exam than their male counterparts. 
Table 4: Self reported students' perception of academic dishonesty related to assignment works

\begin{tabular}{|c|c|c|c|c|c|}
\hline & \multicolumn{5}{|c|}{$\begin{array}{l}\text { Responding "yes" (\%) and } \\
\text { Chi square result }\end{array}$} \\
\hline & Male & Female & Total & $x^{2}$ & $\mathbf{P}$ \\
\hline Wrote assignment for someone else at least once. & 46.2 & 54.3 & 49.4 & 2.19 & 0.085 \\
\hline Paying another person to complete or write an assignment at least once & 22.6 & 32.9 & 26.7 & 4.49 & 0.023 \\
\hline Copying assignments directly from another student. & 6.6 & 17.1 & 10.8 & 9.73 & 0.002 \\
\hline Not involving in group assignments & 11.3 & 25.7 & 17 & 12.36 & 0.000 \\
\hline Working together on an individual assignment & 48.1 & 62.9 & 54 & 7.38 & 0.004 \\
\hline $\begin{array}{l}\text { Copying information directly from web sites, books and other sources } \\
\text { without acknowledging the authors. }\end{array}$ & 34 & 47.1 & 39.2 & 6.15 & 0.009 \\
\hline $\begin{array}{l}\text { Copying information directly from another student's assignment } \\
\text { without consent }\end{array}$ & 22.6 & 24.3 & 23.3 & 0.128 & 0.408 \\
\hline Submitting the same assignment for two or more different courses & 34.9 & 34.3 & 34.7 & 0.014 & 0.499 \\
\hline
\end{tabular}

Table 4 presents the students perceptions of academic misconduct with regard to assignment works. For instance, $49.4 \%$ of the respondents reported that they written an assignment for someone else at least once whereas neatly $27 \%$ of the participants expressed that they paid another person to complete a given assignment at least once. Further about $54 \%$ of the respondents reported that they were working together on individual assignment, 39.2 of the of the students said they were copying information directly from a web site, book and other sources without acknowledging the author and sources of references. Similarly $23.3 \%$ reported that they were copying information directly from another student's assignment without the consent of the hosted student. Finally the result of the self report shows that nearly $35 \%$ of the students claimed that they were submitted the same assignment for two or more different courses.

As presented in table-4, there is significant gender difference in some aspects of how the students perceive the behaviors related to academic dishonesty in the areas of assignment works. The statistical differences were observed in the areas of paying another person to complete assignment works $\left(x^{2}=4.49, P<0.023\right)$, copying assignments directly from another student $\left(x^{2}=\right.$ $9.73, P<0.002$ ), failure of involving in group assignments, working together on an individual assignment $\left(x^{2}=12.36\right.$, $P<0.004)$, and copying information directly from websites, books and other sources without acknowledging the authors and sources of references $\left(x^{2}=6.15, P<\right.$ 0.009 ). The results of this research further shows that female students less likely perceive it was so unethical to commit academic dishonesty related to assignment works than male students.

\section{DISCUSSION}

The primary goals of the higher institutions are to encourage and pursue academic integrity that promotes all rounded personal, social and economical developments. Any form of academic dishonesty at these institutions is presumed to be destructive as it impedes the quality of education and cause professional mediocrity. Thus, this study focused on the students' perception about academic dishonesty and the prevalence of the dishonesty both in the exam related and assignment related practices among Bahir Dar University undergraduate students. Additionally, in this research, it was tested whether there is a significant gender difference on how the students perceived behaviors related to academic dishonesty and engaged in committing the academic dishonesty behaviors.
As compared with the previous researches, the finding of current research demonstrates some inconsistency in exam related academic dishonesty behaviors. For instance Tefere and Kinde (2010) reported $96.4 \%$ of college students had committed academic dishonesty at least once and Maramark and Maline (1993) claimed 95\% of college students had committed dishonesty at least once. But the finding of this research showed that $52.3 \%$ of the students have committed academic dishonesty at least once. However there is some figure differences, the result of the current research shows the large share of students have committed the dishonesty behaviors. But the figure was not as terrible as affirmed by the previous researches. This inconsistency might be observed either due to the consistent application of academic dishonesty policies by the university or the manageable class size in the university.

Even though the number of frauds that were observed in this finding is relatively few as compared with the previous findings, the researcher believes that the academic dishonesty behaviors will continue to be one of the strong problems in the future in our university. The researcher holds this view because among those participated in the academic dishonesty behaviors, only $21.4 \%$ reported they had caught when they were committing the dishonesty either by the invigilators or instructors. Hence, it is strongly required from both the instructors and/or the invigilators to devise creative means of controlling academic dishonesty behaviors can occur using technology or in traditional forms to engender the quality of education and academic integrity.

Among the forms of academic dishonesty that students have committed in the exam session, sending or sharing one's answer with another student was perceived as the strong academic dishonesty behavior that was claimed by $82.4 \%$ of the participants. The least perceived academic dishonesty was not involving in group assignment that was claimed by only $17 \%$ of the participants as academic misconduct behavior. As per reported by the respondents, copying information from unauthorized piece of paper in the exam session was the least commonly committed form academic misconduct as compared with sharing or sending answers. The larger numbers of the students perceive sharing or sending one's answer with others as strong form academic dishonesty whereas only $54 \%$ of the students perceive that working together on individual assignment as committing academic misconduct. In contrast to the perception that sending or sharing one's answer with 
someone else is a serious academic misconduct, $28 \%$ of the students reported that sending or sharing one's answer with other students as a good behavior if not caught. As per obtained from the result of this finding, few students, particularly females, perceive that sending or sharing one's answer with other students as means of helping the weak students academically.

Regardless of figures inconsistency in exam related academic dishonesty behaviors with the previous researches, the current finding supports the findings of Tefera and Kinde (2010) that stated assignment-related dishonesty is much significantly higher among students than exam-related and research-related dishonesty behaviors. With respect to students' perception about assignment work related academic dishonesty behaviors, around half of the students perceive writing assignment works for someone else as not a form of academic dishonesty. In addition, nearly one of four students perceive that paying another person to prepare an assignment or project work as normative academic behaviors whereas one of three students reported submitting the same assignment or project works for more than one courses as a not academic misconduct behaviors. Beyond the prevalence of the academic dishonesty, the findings of this research support that those students who engaged in the practices of the misconduct commit academic dishonesty more frequently as they hope that they never caught by the instructors and invigilators.

With respect to the gender differences in academic dishonesty behaviors, there is significant gender difference in some aspects of behaviors related to the misconducts. The result of chi square shows that female students more frequently practice academic dishonesty behaviors and perceive these misconduct behaviors as less serious problem than male students. The finding of this research is consistent with the finding of Leming (1980) and Lupton et al. (2000) that stated female college students commit academic dishonesty more often than their male counterparts. Particularly female students perceive committing academic dishonesty like giving or sharing exam answer with other students and receiving answer from other students as means academic support. In addition to perception about committing academic dishonesty, female students largely engaged in the practices of the dishonesty as compared with their male counterparts both in exam-related and assignment related dishonesties however the rate of being caught by the invigilator or the instructor is also high among female students.

There is an equivocal notion that was observed in the current finding. First more than half of the students reported that they have had committed academic dishonesty at least once since their university enrollment. But nearly $72 \%$ of these students perceive that cheating in any form is unfair academic behaviors for all students. This finding demonstrates there is a gap between what the students perceive as right and wrong about the academic dishonesty behaviors and what they do in practice. Particularly, there is a larger gap related to the perception about what is right and wrong about the academic misconduct behaviors and the involvement in the academic dishonesty behaviors among female students. In other words, $58 \%$ of female students reported that they had committed academic dishonesty at least once and nearly $78 \%$ of female students perceive academic dishonesty as unfair behavior in any form. In order to clearly understand the reason behind the gap observed the researcher hopes that further research investigation is required.

\section{CONCLUSIONS}

The findings presented in this study validate that academic misconduct is a significant concern that the university need to address. Currently, it would be held that, academic dishonesty would be remaining a subject of great concern in our university as it was a subject of great concern for the past few decades globally. The reason is that majority of the students are practicing the academic dishonesty at least once since their university enrollment and minority of the students have viewed academic dishonesty as less bad practice. The practices of academic dishonesty highly popular on various forms of assignment related activities as compared with the exam related misconducts. But there is a significant gender difference both on the perceptions of academic dishonesty behaviors and practices of committing the dishonesty behaviors in exam related and assignment related works. In other words, majority of female students did not take academic dishonesty as serious problem as compared with their male counterparts. Further few students view academic cheating as means of earning good academic credits. The challenge with these students is that they did not clearly identify what behaviors are and are not basically academic dishonesty. In other words, majority of the students did not know what behaviors were academically dishonesty and what academic behaviors were not.

In the current research, it was observed that there is equivocal students' behavior with regard to the academic dishonesty to moral behaviors and the practical involvement in the dishonesty behaviors. The researcher would prefer to conclude the gap between moral behavior and real practices needs further research to explain the reason why it occurs. Finally, the researcher believes that if the current academic dishonesty situation continues to prevail without a major interference, academic dishonesty will be pursued and will have serious consequences on the quality of education that has been pursuing in our universities.

\section{Conflict of Interest}

Conflict of interest none declared.

\section{REFERENCES}

Bowers, W. (1964). Student dishonesty and its control in college. New York: Bureau of Applied Social Research, Columbia University.

Brimble, M. and Stevenson-Clarke, P. (2005). Perceptions of the prevalence and seriousness of academic dishonesty in Australian universities. Journal of the Australian Educational Researcher 32(3): 19-44.

Brimble, M. and Stevenson-Clarke, P. (2006). Managing Academic Dishonesty in Australian Universities: Implications for Teaching, Learning and Scholarship. Journal of Accounting, Accountability and Performance. 12(1): 32-63.

Bushweller, K. (1999). Student cheating: a morality moratorium. The American School Board Journal 186: 24-32. 


\section{Feyisa Mulisa}

Calabrese, R.L. and Cochran, J. T. (1990). The relationship of alienation to cheating among a sample of adolescents. Journal of Research and Development in Education. Vol. 23, pp, 65-72.

CFAI, (1999). The Center for Academic Integrity by the Office of College Relations at Oakton Community College, Des Plaines, Illinois.

Chiesel, N. (2009). Pragmatic methods to reduce dishonesty in web-based courses. In A. Orellana, T. L. Anderson, and M. r. Simonson (Eds.). The perfect online course: Best practices for designing and teaching (pp. 327-399). Information Age Publishing.

Cortese, A.D. (2003). The Critical Role of Higher Education in Creating a Sustainable Future: Higher education can serve as a model of sustainability by fully integrating all aspects of campus life. pp, 15-22.

Etter, S., Cramer, J.J. and Finn, S. (2006). Origins of Academic Dishonesty: Ethical Orientations and Personality Factors Associated with Attitudes about Cheating with Information Technology. Journal of Research on Technology in Education 39(2): 133-155.

Fawkner, M. and Keremidchieva, G. (2004). Plagiarism, Cheating and Academic Dishonesty - Have You There? International Journal of Information and Security 14:113 137.

Higbee, J.L. and Thomas, P.C. (2002). Student and faculty perceptions of behaviors that constitute cheating. NASPA Journal of Contemporary Issues in Education Research. $4(1): 39-52$.

Jones, L.R. (2011). Academic Integrity and Academic Dishonesty: A Handbook about Cheating and Plagiarism. Florida Institute of Technology: Melbourne, Florida.

Koss, J. (2011). Academic Dishonesty among Adolescents. University of Wisconsin-Stout: M.A. theses.

Leming, J. S. (1980). Cheating behavior, subject variables, and components of the internal-external scale under high and low risk conditions. Journal of Educational Research 74: 83-87.
Sci. Technol. Arts Res. J., April-June 2015, 4(2): 309-315

Lucas, S.G. and Bernstein, D. (2005). Teaching psychology: Step by Step Guide. New Jersey: Lawrence Erlbaum Associates, Inc., Publisher.

Lupton, R.A., Chapman, K.J. and Weisis, J.E. (2000). A Cross- National Exploration of Business Students' Attitudes, Perceptions and Tendencies towards Academic Dishonesty. Journal of Education for Business 75(4): 231235.

Maramark, S. and Maline, M. (1993). Issues in education: Academic dishonesty among college students. Washington, DC: U.S. Department of Education, Office of Research.

Mebratu Mulatu (2014). Academic Dishonesty/ Corruption in the Period of Technology: Its implication for Quality of Education. American Journal of Educational Research 2(11): 1060-1064.

Meizlish, D. (2005). Promoting Academic Integrity in the Classroom. Instructional Consultant at the Center for Research on Learning and Teaching at the University of Michigan.

Roberts, C.J. and Haijew, S. (2009). Issues of Academic Integrity: An Online Course for Students Addressing Academic Dishonesty. MERLOT Journal of Online Learning and Teaching 5(2):182-196.

Spaulding, M. (2009). Perceptions of Academic Honesty in Online versus Face-to-Face Classrooms. Journal of Interactive Online Learning 8(3):183-198.

Stern, E.B and Havlicek, L. (1986). Academic misconduct: Results of faculty and undergraduate student surveys. Journal of Allied Health 15(2): 129-142.

Tefera Tadesse and Kinde Getachew (2010). An Exploration Of Undergraduate Students' Self-Reported Academic Dishonesty At Addis Ababa And Jimma Universities. Ethiopian Journal of Education and Science 5(2): 79-99.

Teshome Yizengaw (2004). The Status and Challenges of Ethiopian Higher Education System and its Contribution to Development. The Ethiopian Journal of Higher Education 1(1): 1-19. 